artigo $]$

\title{
Vestidas para representar: o figurino feminino nos classicos de Hitchcock
}

\author{
Dressed to represent: \\ female costumes in Hitchcock's classics
}

[ MARIANE CARA ]

Mestre em Comunicação e Semiótica pela Pontificia Universidade Católica de São Paulo (PUC-SP), com graduação em Publicidade e Propaganda e técnica em vestuário. Pesquisa temas relacionados à moda, aparência e mídia. E-mail: mari.cara@gmail.com

[resumo] Alfred Hitchcock, além de carregar a reputação de mestre do suspense, é também conhecido pela sua predileção por loiras, que se apresentam sempre impecavelmente vestidas em suas tramas. Para demonstrar seu cuidado com o figurino feminino e a carga simbólica das roupas de suas protagonistas, este artigo analisará quatro clássicos: Janela indiscreta, Um corpo que cai, Os pássaros e Psicose.

\section{palavras-chave}

figurino; Hitchcock; semiótica.

[abstract] Besides the reputation of master of suspense, Alfred Hitchcock is also known as a director who had a predilection for blond women, who are always impeccably dressed in his movies. In order to show Hitchcock's concern with female costume and the symbolic meanings of his leading ladies' clothing, this paper will examine four classics: Rear Window, Vertigo, The Birds and Psycho.

[key words] costume design; Hitchcock; semiotic. 
Embora o cinema seja tema de teorização e crítica desde as primeiras décadas do século $X X$, um dos grandes marcos de seu estudo sistemático se dá nos anos 1950, momento em que é lançada na França a revista Cahiers $d u$ Cinéma, responsável pela divulgação do cinema de autoria, que destaca o papel do diretor no complexo cinematográfico.

Nas décadas posteriores, o estudo da linguagem e das especificidades do cinema avançou, contando com boas literaturas, inclusive em língua portugue$\mathrm{sa}^{1}$. No entanto, o enfoque na constituição do figurino permanece incipiente, conforme aponta Street (2001), tornando-se uma vasta área de investigação.

Com o intuito de investigar algumas particularidades do figurino feminino das décadas de 1950 e 1960, este artigo propõe um retorno ao cinema de autoria, para buscar referências no trabalho de Alfred Hitchcock, um dos mestres consagrados pelo grupo da Cahiers du Cinéma ${ }^{2}$, que nos deixa pistas interessantes sobre 0 ato de compor 0 vestuário de uma personagem.

Nas tramas dirigidas pelo cineasta, principalmente nos filmes de sua fase mais popular, é possível verificar um cuidado excessivo com a aparência. As roupas são meticulosamente idealizadas, segundo os rígidos padrões definidos pelo diretor, com artificios que as tornam bastante codificadas, incluindo especificidades nas formas e cores usadas em cada cena. Para ele, as roupas são consideradas verdadeiras questões de design, que contribuem para o universo onírico da linguagem cinematográfica. Seu cuidado com o vestuário é notado por Rita Riggs (MORAL, 2002), a qual salienta que Hitchcock via em cada cor uma história e uma simbologia, sendo os tons pastel e suaves seus preferidos.

No processo de concepção de um filme, a indicação do figurino era definida ainda na etapa de planejamento - fase em que o diretor dedicava maior parte de seu tempo - e, para garantir na tela o efeito inscrito no roteiro, $\mathrm{Hi}$ tchcock contava com a assinatura de Edith Head para o guarda-roupa de seus clássicos. A escolha de Head é primordial, por se tratar de uma das maiores figurinistas da história do cinema, tendo em seu currículo mais de mil filmes, 34 indicações ao Oscar, oito estatuetas, além de ter colaborado para as grandes revistas de moda americanas.
Com oito semanas para fazer o figurino, Head lia os scripts, rascunhava croquis, conversava com o produtor de cenários para harmonizar as cores dos ambientes e dos trajes; só depois dessas etapas, sentava para desenhar as roupas. Quando tudo estava perfeitamente sincronizado, apresentava as ilustrações para o cineasta que, vez ou outra, alterava ou inseria novas percepções (MORAL, 2002). 0 trabalho de Edith Head para Hitchcock não se resumia aos filmes produzidos, sendo comum a encomenda de consultorias de moda para suas atrizes prediletas, como foi o caso de Vera Miles e Tippi Hedren (FAWELL, 2000).

No jogo de vestir personagens para obter a aparência ideal, o feminino sempre foi o gênero que mais interessou a Hitchcock. Em entrevista para a BBC em $1964^{3}$, o diretor assumiu que seus filmes eram realizados especialmente para agradar o público feminino, que na época totalizava $80 \%$ da audiência nos cinemas. No entanto, esse não era 0 único motivo para seu interesse peculiar pelas mulheres.

Muitas são as literaturas que demonstram a fascinação de Hitchcock pelas atrizes com quem trabalhou, bem como sua obsessão em construir o feminino (MULVEY, 1975; MODLESKY, 1988; GOTTLIEBE, 1997; SPOTO, 1983). Em relação a este universo, John Fawell (2000) comenta sobre a fama de Svengali ${ }^{4}$ que o cineasta cultivou ao longo do tempo. Uma das provas de seu estilo manipulador é a entrevista de 1931, intitulada How I chose my heroines (GOTTLIEBE, 1997), na qual Hitchcock menciona que uma heroína verdadeira deveria ser sensível à sua direção ou, em outras palavras, o tipo de mulher que ele poderia moldar segundo o estereótipo vívido em sua imaginação.

Alfred Hitchcock possuía idéias muito fixas de como deveria ser a "muIher perfeita". No livro Hitchcock on Hitchcock, Gottliebe revela que o diretor aponta sua maneira peculiar de enxergar o feminino ao citar que, para ele, uma mulher digna de admiração deve "não ser uma mulher" (1995, p. 95), ou seja, sem exagerar nos enfeites e no excesso de signos de um visual. Em sua concepção, a feminilidade não deveria estar toda pendurada no pescoço ou exibida através de roupas extravagantes, sendo muito mais interessante o estilo reservado de vestir, como o das loiras glaciais 
do norte europeu, que se mostram frias e inatingiveis à primeira impressão, mas que no mundo privado são verdadeiros vulcões.

São as tais loiras glaciais, misteriosas e repletas de glamour que compõem o rol de protagonistas de seus filmes de suspense, especialmente entre 1954 e 1963, sempre munidas das mais eficazes ferramentas do New Look de Dior: roupas acinturadas, saltos altíssimos e cabelos impecáveis. Nas roupas dessas heroínas vemos, além dos fatores sociais e psicológicos, uma ampla rede de significados, que indica a ação do filme e interfere diretamente no desenrolar da história.

Para ilustrar o minucioso trabalho de composição do figurino das loiras hitchcockianas e a carga simbólica de suas roupas, será apresentada a seguir uma breve análise dos looks de quatro protagonistas: Lisa Caroll Freemont, de Janela indiscreta; Madeleine Elster e Judy Barton, de Um corpo que cai; Melanie Daniels, de Os pássaros, e Marion Crane, de Psicose.

\section{Lisa Caroll Freemont, em Janela} indiscreta: a moda reflete o outro lado da janela

Se o figurino sempre foi importante para Hitchcock, em Janela indiscreta ele excede suas funções tradicionais, tornando-se um sistema complexo e um aspecto crucial da mise-en-scène, como nota Sarah Street (1999).

Já na concepção do filme encontramos, de maneira explícita, dois pontos relevantes da moda enquanto elemento social: o desejo de ver e ser visto. Nesta relação temos o voyeur L. B. Jefferies, que se deleita em observar o mundo alheio, e a exibicionista Lisa Caroll Freemont, que se compraz em ser admirada, utilizando para isso a moda na sua forma mais espetacular.

Lisa é uma típica e ativa nova-iorquina, que trabalha para uma revista de moda e vive nas colunas sociais, desfiles e coquetéis mais concorridos. Para dar conta de tantas atividades, nunca usa a mesma roupa duas vezes e sabe vestir-se corretamente para cada ocasião $0^{5}$. Suas aparições são sempre teatrais, com roupas esfuziantes, em exatos seis looks que demonstram seu cuidado visual.

Com tantos adjetivos relacionados ao mundo da moda, não poderia existir meIhor atriz para o papel de Lisa que Grace Kelly, um dos grandes ícones de estilo dos "anos dourados" de Hollywood e a musa favorita de Hitchcock. Seu feeling para a moda foi notado ainda nas filmagens de Disque M para matar, e, a partir de então, Grace passou a influenciar diretamente no figurino dos filmes hitchcockianos que estrelou, dando assistência direta a Edith Head (STREET, 2002).

As roupas de Lisa podem ser analisadas sob vários aspectos, um dos mais comuns gira em torno do gênero, como foi notado por Laura Mulvey (1975), todavia aqui será abordada outra questão: a reflexividade incessante dos acontecimentos externos em seus looks.

A questão da reflexividade em Janela indiscreta foi primeiramente percebida por Jean Douchet na revista Cahiers du Cinéma, em 1960, quando o crítico entendeu que Jeff seria uma espécie de diretor que constrói - do outro lado da janela - seu próprio cinema (STAM e PEARSON, 1986). E, ao atentarmos para as roupas de Lisa, vemos que a reflexividade não se resume ao contexto do filme, concretizando-se também através da moda.

Em relação às roupas, John Fawell (2000) nota algumas semelhanças na camisola de Lisa, com a da Sra. Thorwald, bem como a repetição da cor verde no tailleur de Lisa e da Sra. Lonelyhearts. A partir dessas duas evidências, foram verificadas outras recorrências que comprovam a indexicalidade da trama com os trajes de Lisa, que carregam consigo os signos dos acontecimentos.

No primeiro traje, composto por uma ampla saia godê branca e echarpe da mesma cor, vemos a indexicalidade com a noiva recém-casada que nos é apresentada minutos antes. Propositalmente, 0 assunto que Lisa e Jeff tratam é exatamente o casamento, aumentando a força do branco que, para não ficar óbvio demais, é pontuado pelo corpete preto, bem como os outros detalhes escuros. No segundo traje, desta vez completamente preto, vemos Lisa em pleno luto pela descoberta do assassinato da Sra. Thorwald. Já no terceiro traje, um tailleur verde mais recatado que as roupas anteriores, temos a associação entre Lisa e a Sra. Lonelyhearts. Na cena, as duas personagens têm as mesmas ações (o ato de servir um jantar) e pode-se concluir que Lisa é uma versão sofisticada da solteirona do filme. 
0 quarto traje é composto por uma camisola de cetim que, além de sugerir a noite de amor entre Jeff e Lisa, conecta diretamente a Sra. Thorwald com Lisa, que se vestem identicamente. Se atentarmos para a camisola e para a aparência da Sra. Thorwald logo no começo do filme, percebemos que Lisa é uma espécie de duplo da mulher que foi cruelmente assassinada pelo marido. Seria este também o fim de Lisa, se casasse com Jeff e se negasse a aceitar o estilo arrojado do marido? Para provar que não, e demonstrar que também possui um jeito intrépido, o quinto traje de Lisa vem estampado com a "prova do crime": as flores que estampam o vestido são iguais às flores do jardim do prédio dos Thorwald, onde Lisa buscará a solução do caso.

0 sexto e último traje é o fechamento da história e, depois de tantas recorrências ao mundo externo, os signos nele compostos retomam o mundo privado de Lisa e Jeff. Enquanto Jeff está com as duas pernas engessadas, Lisa mostra-se no controle da situação, com um look composto por calça jeans, camisa laranja e mocassins, no momento em que lê um livro sobre o Himalaia. 0 enfoque em seu traje masculinizado pode sugerir que Lisa abandonou a moda para seguir uma relação harmoniosa dentro dos padrões aventureiros de Jeff. Porém, a roupa não passa de uma mera falácia para ludibriar Jeff e a audiência que, por alguns segundos, também acredita que ela se transformou completamente para agradar o namorado. A máscara cai quando Lisa deixa de lado o livro e retoma sua leitura da Harper's Bazaar, comprovando que nada mudou, ainda que seu visual diga o contrário.

Se as roupas e a aparência de Lisa foram idealizadas para refletir, como um espelho, o mundo externo que está do outro lado da janela, para as mulheres dos anos 1950, a imagem de Grace Kelly era o referencial em que elas deveriam se espelhar. $\mathrm{E}$ num ambiente de reflexividade sem fim, vemos a operação da moda através do cinema.

\section{Madeleine Elster e Judy Barton em Um corpo que cai: entre a ilusão e a realidade}

Em Um corpo que cai, um dos grandes clássicos do cinema de todos os tempos ${ }^{6}$, Madeleine Elster e Judy Barton são duas mulheres visualmente muito diferentes, mas que ocupam um mesmo corpo: ora cheio de indícios de simplicidade e reali- dade, ora em performance, adornado de detalhes meticulosamente pensados para se tornarem objeto de desejo.

0 filme apresenta uma trama completamente absorvida pela aparência, onde o detetive Scottie (James Stewart) apaixona-se, num sentido fetichista, pela imagem de Madeleine Elster (Kim Novak), composta por tailleur cinza, escarpim, maquiagem sóbria e cabelo loiro. Em linhas gerais, Um corpo que cai é uma infinita metonímia, onde o amor só pode sobreviver ligado às partes visuais que o compõe. A imagem é tão forte no filme, que são raros os diálogos encontrados em seus 124 minutos, dominando a fotografia e a trilha sonora, que dão o tom exato para o desenrolar da paixão objetificada.

Em meio a todo ambiente obsessivo apresentado em Um corpo que cai, verifica-se que o próprio Hitchcock estava enredado pela exatidão da imagem de Madeleine. Na entrevista para François Truffaut, o cineasta admite que a história do filme tem menor importância do que o impacto visual das cenas (TRUFFAUT, 1983). June Van Dyke ${ }^{7}$, responsável pelo Edith Head Collection, comenta que, embora Edith Head apreciasse trabalhar com Hitchcock, nesse caso específico, a figurinista encontrou-se em uma emboscada desafiadora, pelo fato de o cineasta ter idéias muito fixas sobre o figurino, especialmente em relação ao tailleur cinza de Madeleine. Além de Head, Kim Novak também estava descontente com a roupa acinzentada e, de acordo com Sarah Street, depois de tantas reclamações de Kim a respeito do figurino, Hitchcock proferiu a seguinte frase: "You may wear what you like Miss Novak, as long as it's in the script"8 (STREET, 2002. p. 154).

Somada a obsessão pelo traje de Madeleine, temos na película a demonstração de como Hitchcock tratava a questão do figurino em alguns de seus filmes. Na cena em que Scottie leva Judy a uma maison e ao cabeleireiro para reconstruí-la à semelhança de Madeleine, vemos uma reprodução fiel de algumas experiências do próprio Hitchcock com suas atrizes. No livro Alfred Hitchcock - interviews (GOTTIEBLE, 2003) é citada uma entrevista na qual o cineasta comenta que, para o filme Intriga internacional, a figurinista Helen Rose criou um guarda-roupa tão desencontrado, que ele se incumbiu da atividade de escolher as roupas certas para Eva Marie 
Saint, levando-a até a Maison de Bergdorf-Goodman e cuidadosamente supervisionando a escolha de cada peça, nos mínimos detalhes. Na década de 1960, Hitchcock repetiu o feito com Tippi Hedren.

Voltando aos aspectos do filme, no ato de construir a figura feminina de forma idealizada, assistimos na tela o trânsito entre a realidade e a ilusão, sendo a primeira representada por Judy Barton e a segunda pela imagem de Madeleine Elster.

Judy é a naturalidade em carne e osso, uma mulher comum, que se veste de forma desencontrada, usa apenas tecidos baratos e roupas com corte simples. Para mostrar seu descuido, usa maquiagem exagerada e até mesmo vulgar. No momento em que Judy é contratada por Elster para se passar por Madeleine, ela recebe uma repaginação completa, bem aos moldes de filmes como Sabrina e My fair lady, em que um homem de classe transforma uma moça pobre em dama da sociedade. Com a nova máscara, Judy vira mito, arquitetado para encantar Scottie e envolvê-lo num plano sórdido.

Madeleine é a figura perfeita, uma identidade na forma de construto ficticio, que só poderia ter vida no mundo imaginário. Suas roupas têm corte perfeito e tecidos finos, seu cabelo está sempre impecável, sua maquiagem é corretíssima e sua postura, altiva.

No contraste entre o real de Judy e a ilusão de Madeleine, Hitchcock abre mão de um esquema de cores cuidadosamente pensado para o filme. Predominam nele o verde e o vermelho - cores complementares utilizadas em conjunto, para dar um aspecto dramático às cenas e para reforçar o trânsito entre a ilusão e a realidade -, bem como os tons neutros, principalmente o cinza-pálido, que remete ao mundo dos mortos. Nota-se que nas aparições de Madeleine, inclusive em sua reaparição, temos os tons verdes em destaque, que, segundo Truffaut, servem para enfatizar sua característica de fantasma (1983) e por isso irreal.

Hitchcock deixa através de Um corpo que cai algumas pistas intrigantes sobre o construto por meio do fetiche e realça a relevância da vestimenta e dos acessórios na sexualidade e nas relações amorosas.

\section{Melanie Daniels em Os pássaros:a garota alada}

Melanie Daniels (Tippi Hedren) é a garota rica e mimada de 0 s pássaros, uma espécie de Paris Hilton dos anos 1960 que, em prol de uma aventura amorosa, acaba por viver momentos de caos absoluto.

Camille Paglia escreveu um livro que trata do filme, até mesmo no que tange ao figurino e, segundo a autora, Melanie é uma mulher de narcisismo fascinante, armada de alta-costura e maquiagem cintilante (PAGLIA, 1999). Apesar da descrição de Paglia ser condizente com o estilo de roupas da protagonista, podemos ir além e afirmar que Melanie não passa de uma menina vaidosa que se vestiu de pássaro a fim de criar asas e aprontar mais uma de suas travessuras juvenis.

Em todo o filme, que se desenrola em cinco dias consecutivos, Melanie apresenta-se em apenas dois looks, além de uma camisola comprada de última hora. Sua primeira roupa, um tailleur preto salpicado de cinza e camisa branca, já demonstra que seu figurino foi feito para sugerir uma espécie de plumagem. As cores e a apresentação da roupa se assemelham muito ao pássaro negro que está na gaiola do Pet Shop e que será observado por Mitch (seu alvo amoroso), antes mesmo de 0 advogado dirigir o olhar a Melanie.

Depois de uma paquera pouco convencional, Melanie decide presentear Mitch e sua irmã Cathy com um casal de lovebirds (periquitos) e, para cumprir a missão, a "mulher-pássaro" veste a próxima plumagem, que lhe acompanhará até o fim do filme: tailleur verde-pálido, escarpim marrom de saltos ofegantes, bolsa da mesma cor das luvas, lábios e unhas em vermelho-carmim, cabelos loiríssimos em um coque que lembra as asas de um pássaro e jóias de ouro. Vemos em sua aparência a repetição exata das cores e formas dos periquitos que leva consigo, sendo que o cuidado para apresentá-la como a cópia de um lovebird é tão grande que, para finalizar o look, ela veste um casaco de vison bege, com suaves listras marrons que remetem diretamente à gaiola dourada que prende os tais passarinhos.

0 figurino de Melanie em Os pássaros funciona como uma espécie de joguete, onde a garota decidiu se fanta- 
siar, tal como uma criança que se veste de super-herói e acredita que será capaz de voar. Melanie não consegue alçar um alto vôo e, a cada ataque dos pássaros reais, sua brincadeira vai perdendo a graça e sua fantasia vai se esgarçando, até o ponto de virar trapos, que mal lembram sua sofisticação e narcisismo.

Totalmente fora do controle, Melanie aparece no fim do filme como uma velha boneca de pano, com o rosto pálido e coberto por faixas. Para evitar que ela se machuque ainda mais, os Brenner prendem-na novamente em seu "casaco-gaiola" e seguem sem destino, ou ao menos a um destino que não conhecemos.

\section{Marion Crane de Psicose: lingeries que evocam e provocam}

Se existe uma loira fugaz nos filmes hitchcockianos, sem dúvida seu nome é Marion Crane (Janet Leigh), a protagonista de Psicose que se despede do filme depois de apenas 45 minutos de ação, num dos crimes mais famosos da história do cinema. Mesmo atuando em tão poucas cenas, seu figurino é extremamente relevante, pela ousadia e quebra de tabus tão consolidados na Hollywood da época.

Marion é uma secretária de Phoenix que vive em crise psicológica, não encontrando um denominador comum entre a conduta ética de honestidade e sua compulsão pela transgressão. Suas roupas são simples, como de qualquer trabalhadora de sua faixa etária, desenhadas da forma mais realista possivel, a partir de uma pesquisa minuciosa do guarda-roupa de uma secretária semeIhante a personagem (PAGLIA, 1999). Embora esse cuidado seja relevante para um figurino fiel, o grande trunfo visual de Marion em Psicose não reside no aspecto realista de suas roupas, mas na provocação moral de suas lingeries.

Na década de 1960 era inconcebível vermos uma personagem envolvida em um tórrido romance extraconjugal, ainda mais em se tratando da protagonista, que em grande parte do tempo aparece seminua. Ciente dos limites da censura hollywoodiana, Hitchcock resolveu ousar através de Marion, vestindo-a com lingeries provocantes, que demonstram seu estado psicológico.

Sua primeira cena é um encontro de amor estrategicamente marcado no horário do almoço, onde ela apresenta sua "disponibilidade" para a vida dúbia. De acordo com Rita Riggs ${ }^{9}$, a então fi- gurinista do filme, sua lingerie é branca para evocar seu estado de pureza e inocência, pois ainda que ela se encontre em uma atitude suspeita, não cometeu nenhum delito, merecendo uma cor de candura.

Na seqüência, Marion se vê enredada pelo roubo dos dólares e por este motivo suas lingeries mudam automaticamente de cor, devendo ser pretas para evocar seu estado de transgressora, agora sob o signo da criminalidade.

Depois de vermos repetidamente seu corpo envolto em lingeries sensuais, somos apresentados à nudez de Marion quando a personagem se arrepende do roubo e, com a alma tranqüila, resolve tomar um banho relaxante, que a lavará de todos os erros cometidos. Despida de suas roupas, Marion parece aliviada e livre dos tormentos mentais que anteriormente foram representados por sua roupa íntima.

Feliz, porém vulnerável demais, não percebe o perigo e acaba por sair de cena morta, antes mesmo de viver a respeitabilidade, a castidade e a tão sonhada vida pública junto de seu amante Sam.

Do corpo de Marion resta apenas seu olhar em um grande close-up, tal como o olhar que nós, espectadores, dirigimos a ela em seu jogo de vestir e despir.

Vemos nos filmes de Hitchcock, aqui apresentados, a escolha de um elemento de destaque a ser enfocado na construção do figurino da protagonista. Em Janela indiscreta o destaque é dado ao exibicionismo que o universo da moda guarda em seu bojo; em Um corpo que cai o elemento principal é o ato de criar uma identidade por meio do traje; em Os pássaros a ênfase está no visual da personagem funcionando como fantasia-disfarce; e em Psicosea tônica reside na sensualidade da lingerie, que se encerra no corpo nu, desprovido de toda a artificialidade e de todos os construtos culturais que são representados através das roupas.

Além desses elementos simbólicos, vale destacar que o intuito de Hitchcock e Edith Head ao vestir as loiras glaciais de forma espetacular ultrapassava os limites das telas, com a finalidade de popularizar uma determinada concepção do feminino, utilizando para isso a união entre os lançamentos parisienses e os fetiches e idiossincrasias do cineasta a respeito da moda.

Com um projeto estético consistente, o estilo dos figurinos hitchcockianos 


\section{NOTAS}

[1] Uma boa coletânea sobre a Teoria do Cinema encontra-se em Teoria contemporânea do cinema, Volumes 1 e 2 , organizada por Fernão Pessoa Ramos, da Editora Senac (São Paulo). 2005.

${ }^{[2]} 0$ grupo de críticos que compôs a revista em seu lançamento tinha como cabeças nomes como JeanLuc Godard e François Truffaut.

${ }^{[3]}$ A entrevista está disponivel em: <http://www.youtube.com/watch?v=ydvU64L758cCtfeature=related> Acesso em: 04 fev 2008.

${ }^{[4]}$ Svengali é um personagem literário criado por George du Maurier, que usava hipnose para controlar uma cantora que só conseguia se apresentar quando estava sob seu transe. 0 termo se popularizou e atualmente é usado para um diretor ou chefe que exercita grande dominação em relação a seus liderados.

${ }^{[5]}$ Nunca usar a mesma roupa duas vezes e saber vestir-se corretamente para cada ocasião são duas frases citadas no filme, entre tantas outras, que demonstram o quanto Lisa está conectada com o universo da moda.

${ }^{[6]} \mathrm{Em}$ 2007, o American Film Institute apresentou a lista dos 100 melhores filmes de todos os tempos e Um corpo que cai ficou classificado em 9 lugar.

[7] Comentário de June Van Dyke, extraído do making of do filme Vertigo, disponível no DVD do filme. HITCHCOCK, Alfred (direção). Um corpo que cai (Vertigo), USA, 1958. Produtor: Paramount Pictures/Alfred J. Hitchcock Productions. DVD comercializado por Universal Pictures.

${ }^{[8]}$ Tradução da autora: Você pode vestir o que preferir, Senhorita Novak, contanto que essa roupa esteja no script. ${ }^{[9]}$ Comentário de Rita Riggs, extraído do making of do filme Psicose, disponível no DVD do filme. HITCHCOCK, Alfred (direção). Psicose (Psycho), USA, 1960. Produtor: Shamley Productions/ Paramount Pictures. DVD comercializado pela Universal Pictures.

\section{REFERÊNCIAS}

FAWELL, John. Fashion dreams - Hitchcock, women, and Lisa Fremont. Literature Film Quarterly, 2000. GOTTLIEBE, Sidney (editor). Hitchcock on Hitchcock - selected writings and interviews. Bekerley: University of California Press, 1997.

. Alfred Hitchcock: interviews. Mississipi: University Press of Mississipi, 2003.

MODLESKY, Tania. The women who knew too much - Hitchcock and feminist theory. Nova York: Methuen, 1988

MORAL, Tony Lee. Hitchcock making of Marnie. Manchester University Press, 2002.

MULVEY, Laura. Visual pleasure and narrative cinema. Originally Published - Screen 16.3, Autumn 1975

PAGLIA, Camille. Os pássaros (The birds). Tradução de Jussara Simões. Rio de Janeiro: Editora Rocco, 1999.

SPOTO, Donald. The dark side of genius - the life of Alfred Hitchcock. Boston: Little Brown, 1983.

STAM, Robert e PEARSON, Roberta. "Hitchcock's rear window: reflexivity and the critique of voyeurism". In: DEUTELBAUM Marshall, 1986.

STREET, Sarah. "Hitchcock Haberdashery". In: GOTTLIEBE, Sidney (editor). Hitchcock on Hitchcock selected writings and interviews. Bekerley: University of California Press, 1997.

"The dresses had told. Fashion and femininity in rear window". In: BALTON, John (editor). Alfred Hitchcock rear window. Cambridge: Cambridge University Press, 1999.

Costume and cinema - dress codes in popular film. Londres: Wallflower Press, 2001.

TRUFFAUT, François. Hitchcock. Nova York: Simon \& Schuster, 1983.

\section{FILMOGRAFIA}

HITCHCOCK, Alfred (direção). Janela indiscreta (Rear window), USA, 1954. Produtor: Paramount Pictures DVD comercializado por Universal Pictures.

HITCHCOCK, Alfred (direção). Um corpo que cai (Vertigo), USA, 1958. Produtor: Paramount Pictures/Alfred J. Hitchcock Productions. DVD comercializado por Universal Pictures.

HITCHCOCK, Alfred (direção). Psicose (Psycho), USA, 1960. Produtor: Shamley Productions/ Paramount Pictures. DVD comercializado por Universal Pictures.

HITCHCOCK, Alfred (direção). Os pássaros (The birds), USA, 1963. Produtor: Universal Pictures/Alfred J. Hitchcock Productions. DVD comercializado por Universal Pictures. 